\title{
Application of Orbital Sonography in Neurology
}

\author{
Michael Ertl' ${ }^{1}$, Maria-Andreea Gamulescu ${ }^{2}$ and Felix Schlachetzki ${ }^{1}$ \\ ${ }^{1}$ Department of Neurology, University of Regensburg, Bezirksklinikum Regensburg \\ 2Department of Ophthalmology, Regensburg University Medical Center
}

Germany

\section{Introduction}

Color-coded duplex sonography is a well established non-invasive method for vascular and parenchymal examination in a wide range of neurological disorders including stroke, cerebral venous thrombosis and degenerative diseases, amongst others. Considering development, cell types and vascular structures as well as pathology and pathophysiology, high similarities and interactions exist between the central nervous system (CNS) and the eye.

When applied to the eye and the orbit, high-resolution color-coded duplex sonography (OCCS) may depict a variety of pathologic alterations such as papilledema or central retinal artery occlusion, that represent manifestation of CNS disorders (i.e. raised intracranial pressure) or systemic diseases (i.e. atherothrombotic/ thrombembolic occlusions), respectively. Although easily accessible, OCCS has not yet gained widespread use in daily neurological practice despite the fact that most modern ultrasound systems are capable of performing such an endeavor. However, this technique may be a very helpful, fast and powerful diagnostic procedure in addition to the diagnostic battery needed for unraveling specific CNS or systemic diseases.

In this book chapter article we highlight different aspects of OCCS and concentrate on methods and diseases relevant for neurologists. The differential diagnosis of orbital tumors (e.g. lymphoma, optic sheath meningeoma, pseudotumor orbitae, myositis, and others) or vascular abnormalities (e.g. varicosis, superior orbital venous dilatation in arterio-venousfistula) will not be discussed. The first part introduces the reader to the technical requirements, restraints and safety for performing sonography of the eye. Normal relevant anatomy as well as normal values will be given. The second part focuses on common vascular pathologies such as central retinal artery occlusion in the context of suspected giant cell arteritis as well as swelling of the optic nerve and papilledema linked to raised intracranial pressure. Being a fairly young technique, few studies employing OCCS exist, yet a large variety of interesting pathology and variations may be found as exemplified in the third and final part of the chapter.

Ocular color-coded duplex sonography is a fascinating technique with high potential for neurologists in differential diagnosis and therapy of an expanding variety of acute and chronic CNS disease. 


\section{Technique and safety considerations}

Orbital sonography can be easily performed using most color duplex ultrasound systems equipped with high frequency linear array transducers. Since the optic lens as well as the vitreous do not absorb significant ultrasound energy and make near field artifacts virtually impossible, commonly used transmit frequencies in neurology from 7 to $15 \mathrm{MHz}$ may be used. According to the physics of wave propagation in tissue and the resulting axial and lateral resolutions, the general aim is to apply high frequencies up to $14 \mathrm{MHz}$ or more. The acoustic output of the ultrasound systems needs to be adjusted to the requirements of orbital sonography according to the ALARA principle (,as low as reasonable achievable') in order to avoid damage to the lens and retina (Toms 2006). The main biological effects would be cavitation and temperature increase, the latter being dependent from the insonation time. In animal experiments harmful effects of ultrasound acoustic power to ocular structures (esp. lens and choroid) could be demonstrated (Lizzi et al. 1978). Therefore, current guidelines released by the FDA limit the acoustic output to temporal average intensities of up to $50 \mathrm{~mW} / \mathrm{cm}^{2}$ and a mechanical index (MI) of up to 0.23 (Food and Drug Administration 2008). An on-screen indicator of ultrasonic output, the MI is a measure of the likelihood that a clinically important non-thermal biological effect may occur during a diagnostic examination (American Institute of Ultrasound in Medicine 2000). However, most examinations last less than 5 minutes for each eye, hereby limiting the possibility of thermal damage. In order to prevent cavitation effects, the settings for orbital sonography may be as follows:

- $\quad$ B-mode - transmit frequency $14 \mathrm{MHz}$, mechanical index $(\mathrm{MI})=0.23$, single focal zone at $2.5 \mathrm{~cm}$, bandwidth $74 \mathrm{~dB}$;

- C-mode - transmit frequency $10 \mathrm{MHz}, \mathrm{MI}=0.23$, color scale optimized for low velocities, no wall filter;

- $\quad$ pw-Mode - transmit frequency $2 \mathrm{MHz}, \mathrm{MI}=<0.23\left(<0.44^{*}\right)($ Tab. 1$)$.

\begin{tabular}{|l|l|l|l|}
\hline & B-mode & C-mode & pw-mode \\
\hline transmit frequency & $14 \mathrm{MHz}$ & $10 \mathrm{MHz}$ & $2 \mathrm{MHz}$ \\
\hline mechanical index $(\mathrm{MI})$ & $<0.23$ & $<0.23$ & $0.23\left(<0.44^{*}\right)$ \\
\hline single focal zone & $2.5 \mathrm{~cm}$ & & \\
\hline bandwidth & $74 \mathrm{~dB}$ & & \\
\hline $\begin{array}{l}\text { Special } \\
\text { recommendations }\end{array}$ & $\begin{array}{l}\text { color scale } \\
\text { optimized for low } \\
\text { velocities } \\
\text { no wall filter }\end{array}$ & \\
\hline
\end{tabular}

Table 1. Machine parameters in B-mode, C-mode and pw-mode, *often the lowest output value

It needs to be kept in mind that most color-duplex machines require reduction of the acoustic output in each mode, that is the B-mode, color-mode and spectral Doppler-mode (the latter might not display values below 0.44).

During the examination the patient lies in supine position with the eyes closed (Fig. 1a). A layer of acoustic gel is applied to the closed lids, the transducer is placed on the upper and 
slightly lateral eye-lids with the examiner's hand resting on the orbital margin to minimize pressure on the globe (Fig. 1b/c). To optimize the display of anatomical stuctures, esp. the optic nerve, the transducer is positioned a little on the temporal side and the patient is asked to try to look straight even with the eyes closed. Pressure on the globe should be as low as possible as this might result in a decrease in blood flow velocity of retro-orbital vessels (Tranquart et al. 2003). The optic nerve presents as a hypoechogenic structure beyond the globe in this horizontal scanning plane and the optic disc and provides an anatomical landmark for the ultrasound examination (Fig. 2).

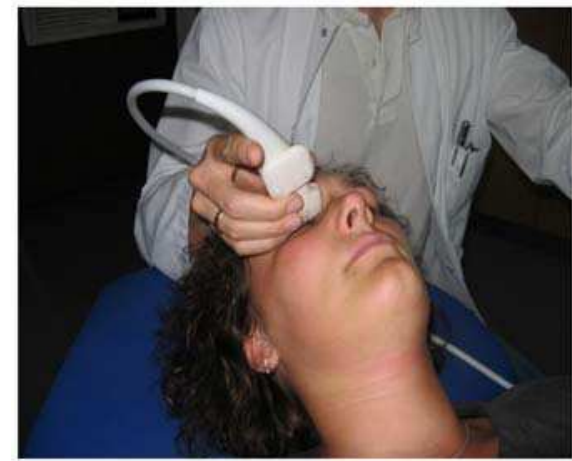

(a)

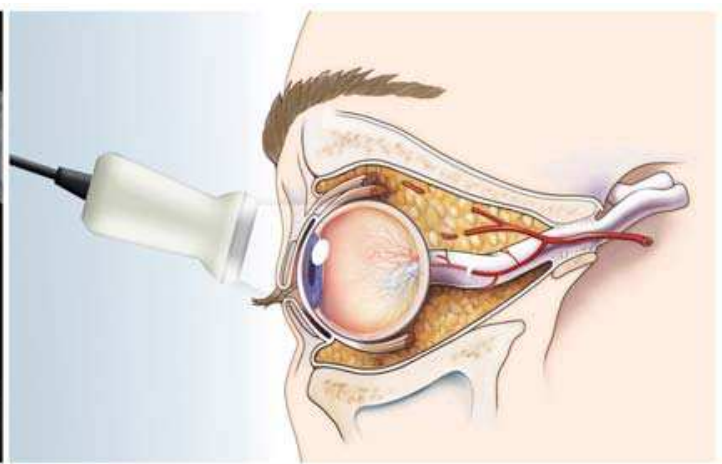

(b)

Fig. 1. Standard examination parameters. (a) Patient lies in supine position with the eyes closed. (b) The transducer is placed on the upper eye-lids (slightly lateral) with the examiner's hand resting on the orbital margin. (c) Illustration of correct transducer positioning and anatomical overview. Copyright ${ }^{\circledR}$ M.Ertl, with permission
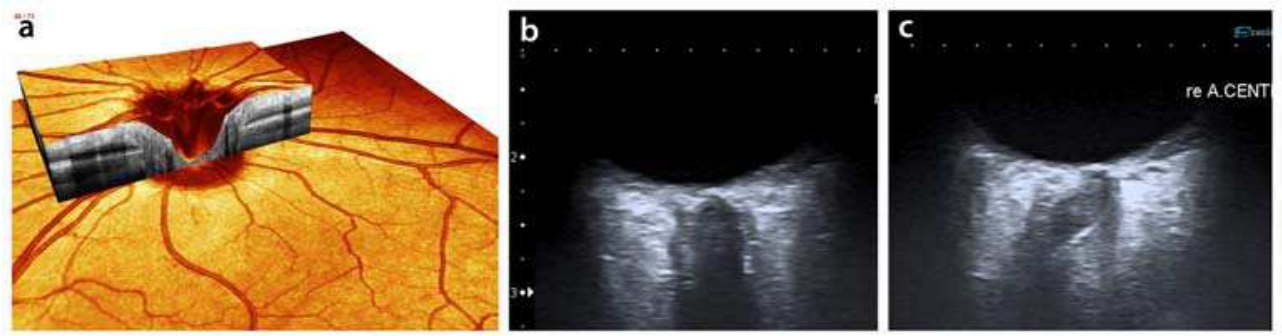

Fig. 2. Anatomical landmarks for ultrasound examination (a) Ocular coherence tomography (Spectralis $®$, Heidelberg Engineering, Germany) excellently demonstrating the retinal vasculature and layers of the retina. However, inlay demonstrates limited penetration beyond the level of the retina. (b) High resolution B-mode sonography in the horizontal and lateral scanning plane presenting the optic nerve as a hypoechogenic structure beyond the retina surrounded by the hyperechoic subarachnoid space and the hypoechoic dura mater. The optic nerve provides an anatomical landmark for the ultrasound examination. For anatomical correlates see Figure 3. (c) In a strictly axial horizontal image plane, the optic nerve appears curved limiting the diagnostic accuracy of optic nerve diameter measurements 
In order to enable side-to-side comparison, the left side on the monitor pictures the nasal orbit.

\section{Vascular diagnostics}

The central retinal artery (CRA), a distal branch of the ophthalmic artery, enters the optic nerve approximately 1-1,5 cm distal from the globe coming from the dorsolateral direction (Fig. 3). It supplies the retina and can be identified together with its parallel running central retinal vein $(\mathrm{CRV})$ using the color-mode.

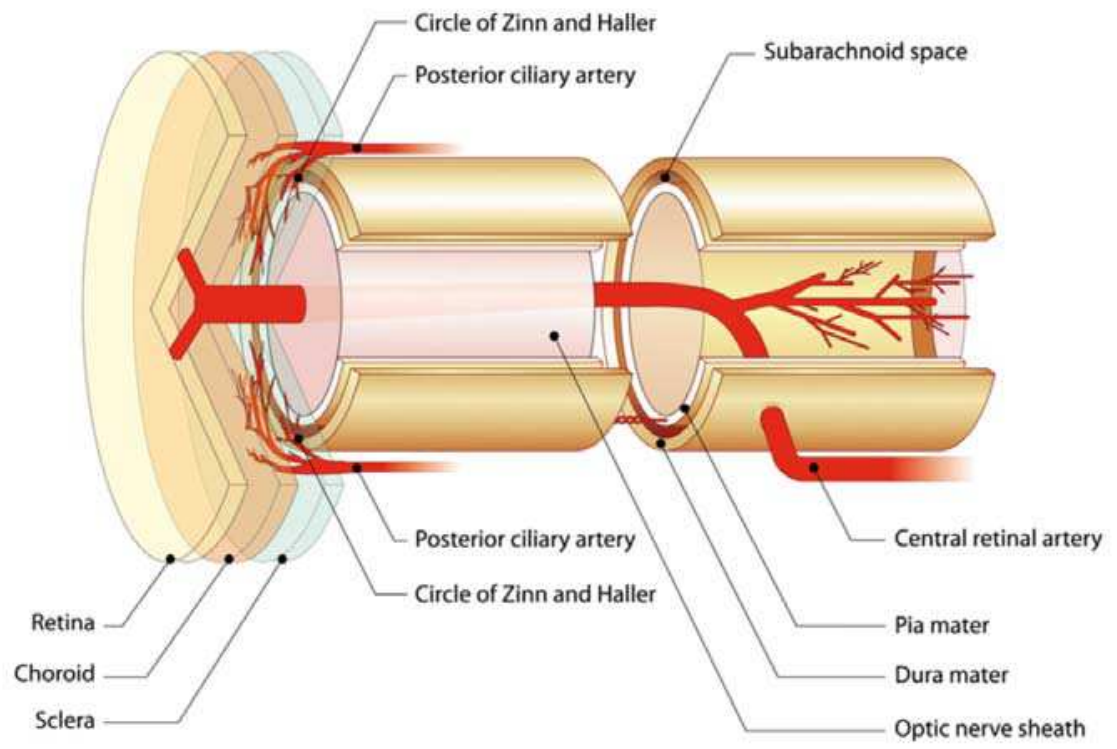

Fig. 3. Anatomy of retrobulbar structures: vascular supply of the retina and the optic nerve and sorrounding structures. Copyright ${ }^{\circledR}$ M.Ertl, with permission

Normal values were first established by Lieb et al. 1991 and are summarized in Table 2 (Lieb et al. 1991). For best visualization, the probe should be positioned as described above with a good view of the optic nerve in the axial plane. The focus zone should be set in the level of the optic disc. In color-mode the pulse-repetition-frequency should be adjusted to register low-flow signals of the central retinal artery and the central retinal vein. Color gain has to be adapted according to the flow velocities as well as to reduce background noise and color signals generated by minimal eye movements (movement artifacts) (Fig. 4).

\begin{tabular}{|l|l|}
\hline Orbital vessel & Mean \pm SD Blood Flow, cm/s (Range) \\
\hline Central retinal artery & $10.3 \pm 2.1(6.4-17.2)$ \\
\hline Central retinal vein & $2.9 \pm 0.73(1.9-5.4)$ \\
\hline Ophthalmic artery & $31.4 \pm 4.2(23.5-39.8)$ \\
\hline Posterior ciliary artery & $12.4 \pm 4.8(1.4-22.7)$ \\
\hline
\end{tabular}

Table 2. Maximum systolic blood flow velocities in orbital vessels 

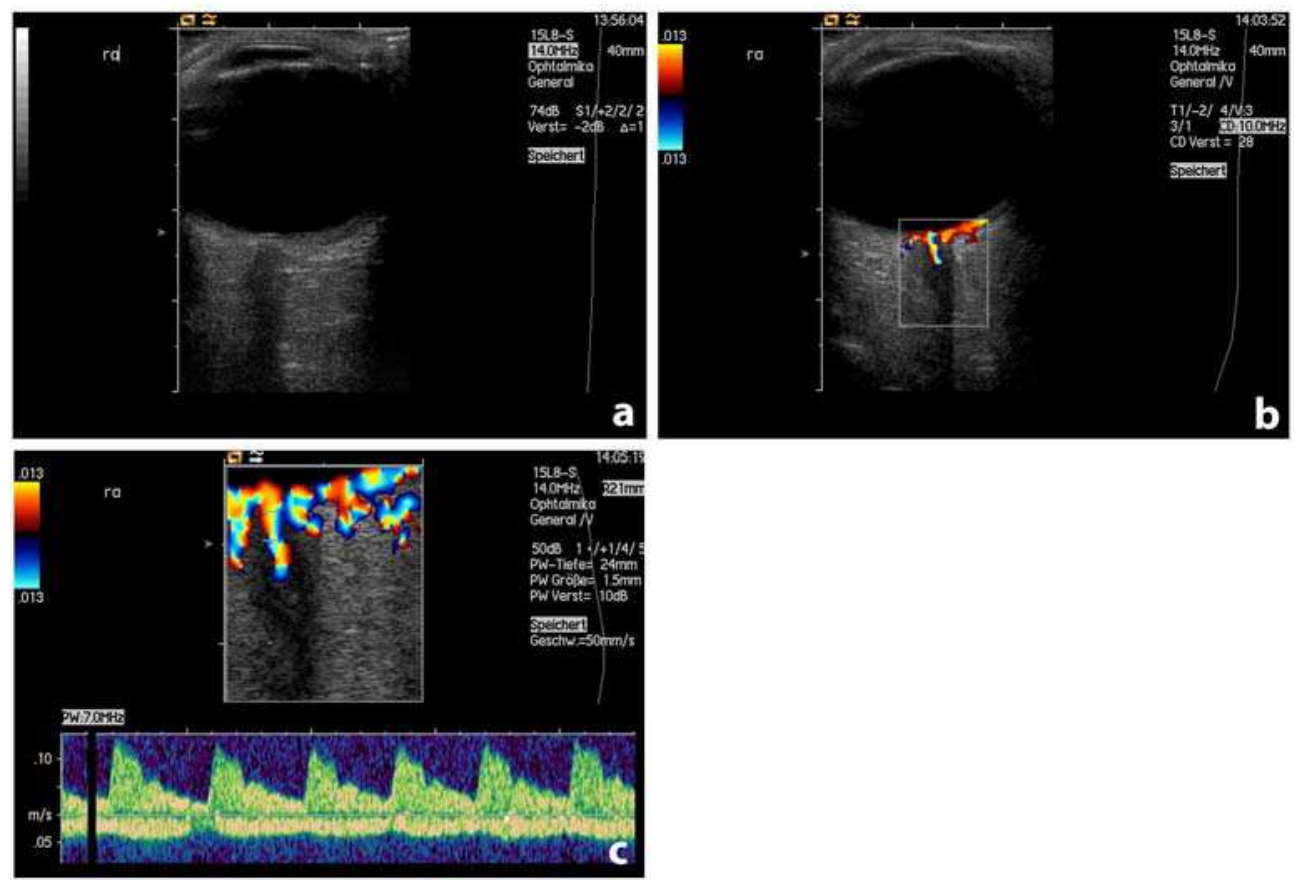

Fig. 4. Normal retrobulbar findings using high-resolution ultrasound in B-mode, Color-mode and spectral Doppler: B-mode: (a) The optic nerve presents as a hypoechogenic structure beyond the retina and the optic disc (b) Color-coded Duplex mode: central retinal artery (CRA) accompanying the optic nerve; section of retinal vessels from the posterior ciliary artery and the Circle of Zinn and Haller (c) Spectral-Doppler with Duplex-mode: normal spectrum of the CRA with peak-systolic velocity of $10.3 \pm 2.1 \mathrm{~cm} / \mathrm{s}$ and the underlying central retinal vein with peak-systolic velocity of $2.9 \pm 0.73 \mathrm{~cm} / \mathrm{s}$ (see also Table 2)

Alterations of flow in the CRA can occur in a variety of circumstances causing decreased visual acuity. In elderly patients this is mainly due to hypoperfusion or occlusion of the CRA caused by thrombo-embolic events (Brown and Magargal 1982; Gold 1977) or as CRA involvement in temporal arteritis (TA) (McFadzean 1998). In case of a central retinal artery occlusion (CRAO) a hyperechoic structure might be depicted in the optic nerve head, representing a fresh cholesterol embolus (Pfaffenbach and Hollenhorst 1972), which was termed "spot sign" by Schlachetzki and colleagues (Schlachetzki et al. 2010) (Fig. 5a). This finding is accompanied by absent flow in the CRA, whereas flow in the CRV is still detectable (Fig. 5b). The incidence of this phenomenon was first investigated by Foroozan et al. (Foroozan et al. 2002). In their retrospective study a "spot sign" occurred in 31\% of cases of sudden ocular blindness. However, in an ongoing prospective study we found an incidence of up to $90 \%$ in patients with CRAO (Ertl et al., submitted).

In patients with TA, either reduced (Fig. 6a) or absent flow in CRA (Fig. 6c) was evident. The diagnosis of TA can by firmly supported by hypoechoic vasculitic vessel wall changes in the temporal arteries (so called "halo"-sign) (Arida et al. 2010), but the negative predictive 

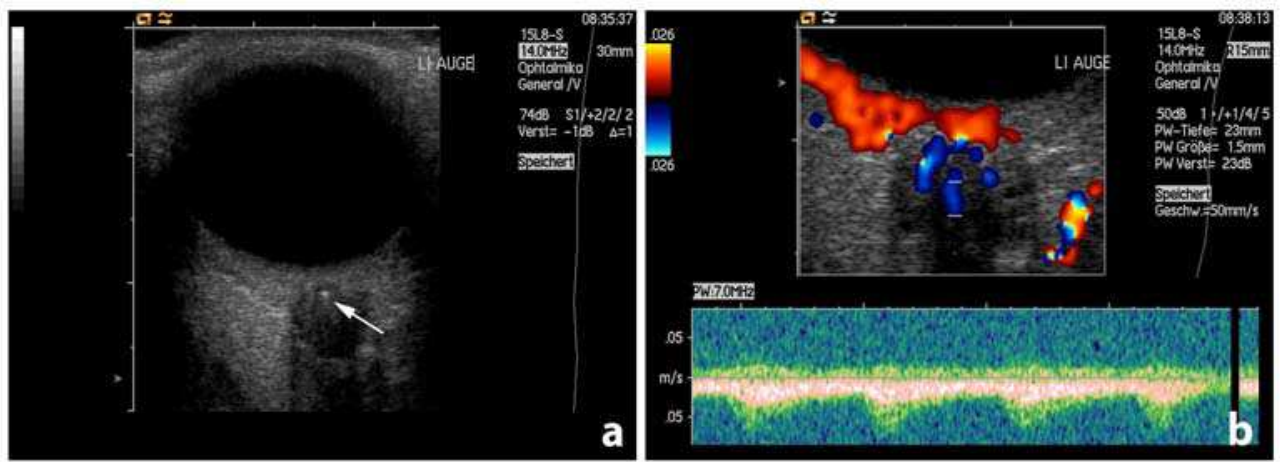

Fig. 5. Ultrasound findings in a patient with embolic central retinal artery occlusion.

(a) B-mode: Hyperechogenic "spot sign“ in the optic nerve head (arrow), representing an embolus in the distal CRA. (b) Color-Duplex- and spectral Doppler-mode: absent flow in the CRA with persistant perfusion of the central retinal vein
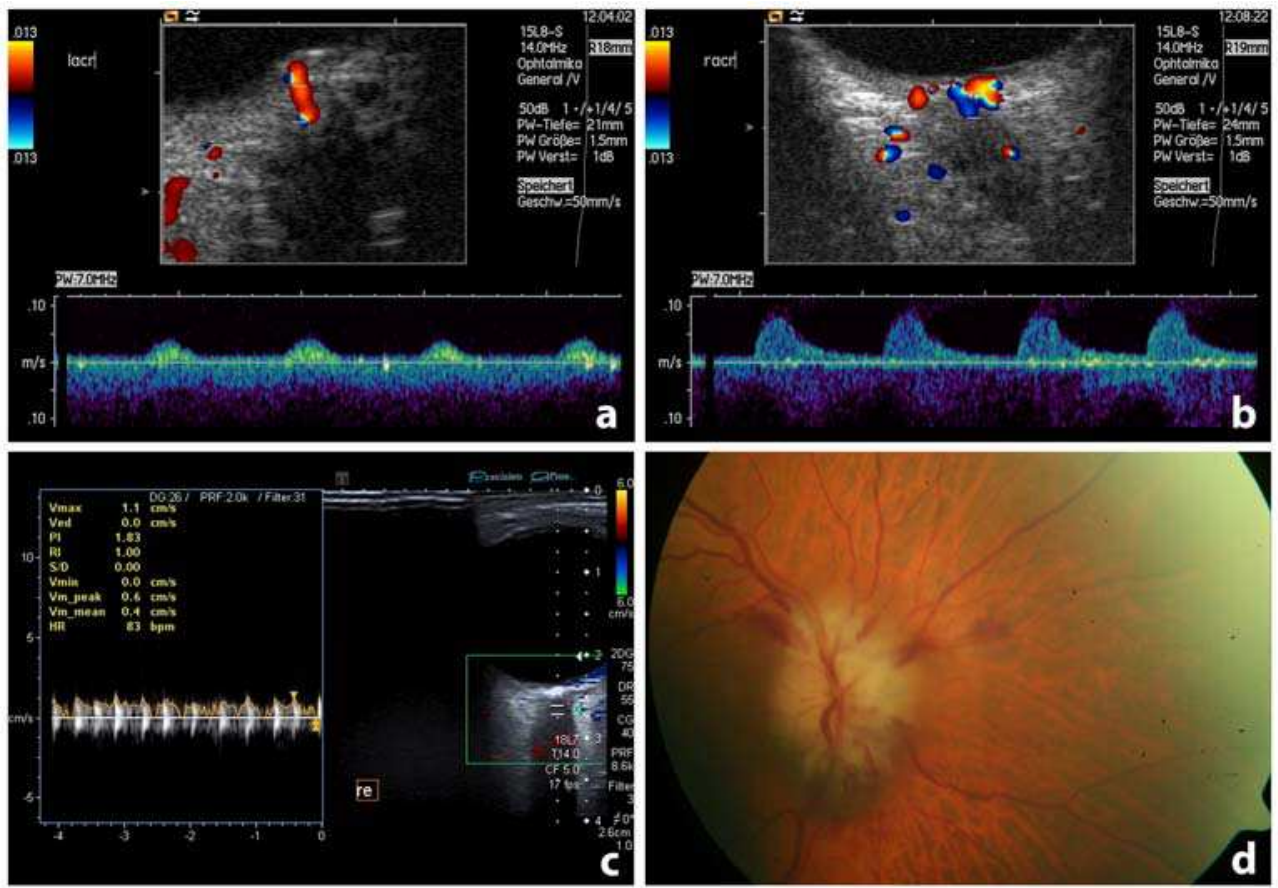

Fig. 6. Ultrasound and funduscopic findings in patients with central retinal artery occlusion due to temporal arteritis. (a) Patient 1: Color-Duplex- and spectral Doppler-mode: Pseudovenous flow in the affected CRA. (b) Patient 1: Color-Duplex- and spectral Dopplermode: normal flow in the unaffected contralateral CRA. (c) Patient 2: Color-Duplex- and spectral Doppler-mode: zero-flow in the affected CRA. (d) Patient 2: fundoscopy: blurred rim of optic disc, optic disc edema and hyperemia, small splinter hemorrhage 
value is only $68 \%$ and thus far not sufficient to rule out that disease. In patients with sudden retinal blindness and borderline symptoms for TA (only 2-3 positive ACR-criteria), a visible "spot sign" could be very helpful to rule out vasculitis, as could be demonstrated in the above-mentioned prospective study (Ertl et al., submitted).

Quick and sound differentiation of both etiologies is important for the initiation of specific treatments: thrombo-embolic occlusions need to be treated with platelet-inhibitors and high doses of cholesterol-lowering drugs, among control of additional cerebrovascular risk factors, whereas TA requires a sufficient and long-lasting steroid therapy to prevent secondary blindness of the unaffected eye.

Absent or reduced flow in the central retinal artery should lead to detailed workup looking for sources of cardiac emboli (ECG, cardiac echo, long term ECG, holter monitoring) and artherosclerosis (IMT using carotid ultrasound, presence of hemodynamically relevant carotid stenoses, etc.). Muller et al. found that in the majority of patients with ocular syndromes and ICA-stenosis greater than 50\% (according to the NASCET-classification (Arning et al. 2010)), the ICA-stenosis was located on the ipsilateral side (Muller et al. 1993). Reversely, other studies could show a significant flow reduction in the ophthalmic artery and the central retinal artery in patients with ICAstenosis of $70 \%$ or more (NASCET-classification) (Paivansalo et al. 1999). Consequently peak systolic velocity in the CRA and the posterior ciliary artery improved after carotid endarterectomy (Mawn et al. 1997).

A major advantage of OCCS is the visualization of structures lying behind the retina. Indirect fundoscopy and photodocumentation, common tools for ophthalmic investigations, are excellent methods to display pathologies up to the level of the retina or the choroid. Unfortunately, these techniques lack sensitivity or depth penetration beyond the choroid, and thus cannot elicitate the underlying cause of CRAO. Conventional A- and B-mode ultrasound systems for visualization of the globe and orbit used in opthmalmology have transmit frequencies between 10 to $20 \mathrm{MHz}$. The last mentioned very high frequency has difficulties to penetrate beyond the choroid, and often these equipment lack Doppler or color-coded Doppler capabilities.

\section{Assessment of intracranial pressure}

Elevation of intracranial pressure (ICP) is a common phenomenon caused by a variety of neurological disorders as brain tumors, intracranial bleedings, or head trauma. Elevated ICP can be associated with life threatening conditions, e. g. brainstem herniation. Therefore these critically ill patients need to be monitored regularly to an extend of several times a day. Neuroimaging techniques as computed tomography (CT) and magnet resonance imaging (MRI) can help to assess raised ICP but have their diagnostic limitations as well (Hiler et al. 2006; Winkler et al. 2002) and require a potentially harmful patient transport. The gold standard for ICP measurement remain to be invasive intracranial devices: in addition to the need for neurosurgical operation and contraindications (e.g. thrombocytopenia) these methods are associated with certain complications as hemmorhage, infections and shunt malfunction (Brain Trauma Foundation 2000).

OCCS might be an interesting bedside alternative for follow-up examination of these critically ill patients. Several studies investigated the utility of measurements of the optic 
nerve sheath diameter (ONSD) as an indicator for ICP measurement and management (Antonelli et al. 2009; Galetta et al. 1989; Hansen and Helmke 1997). The optic nerve as part of the central nervous system (CNS) is surrounded by cerebrospinal fluid (CSF), and thus communicates with the inner and outer subarachnoid space. Therefore, elevation of ICP can be assessed by measuring the ONSD, but also the intraocular prominence of the papilla.

The transducer is positioned as described in the technical segment, the beam is focused on the area behind the papilla and the optic nerve should be depicted in the axial plane. The optic nerve sheath is demonstrated as a thin bilateral hyperechogenic line surrounding the hypoechogenic optic nerve (Fig. 7). Due to trabecular structures in this compartment the optic nerve sheat (ONS) reflects a high fraction of ultrasonic energy, while the optic nerve runs in line with the ultrasound beam without reflection. The ONSD is measured $3 \mathrm{~mm}$ behind the optic disc by measuring the distance between the hyperechogenic borders of the ONS (Fig. 7). Most authors suggest normal values $<5,0 \mathrm{~mm}$ for patients $>1$ year (Ballantyne et al. 2002; Blaivas et al. 2003; Girisgin et al. 2007; Helmke and Hansen 1996; Newman et al. 2002; Tayal et al. 2007; Tsung et al. 2005). A reliable cut-off value to predict an ICP > $20 \mathrm{cmH}_{2} \mathrm{O}$ seems to be $5,7-6,0 \mathrm{~mm}$ with a sensitivity of $87-95 \%$ and a specificity of $79-100 \%$ (Geeraerts et al. 2007; Geeraerts et al. 2008; Soldatos et al. 2008; Watanabe et al. 2008). A meta-analysis of six studies having compared the reliability ONSD-measurements with classical invasive ICP monitoring in patients with intracranial hemorrhage and traumatic

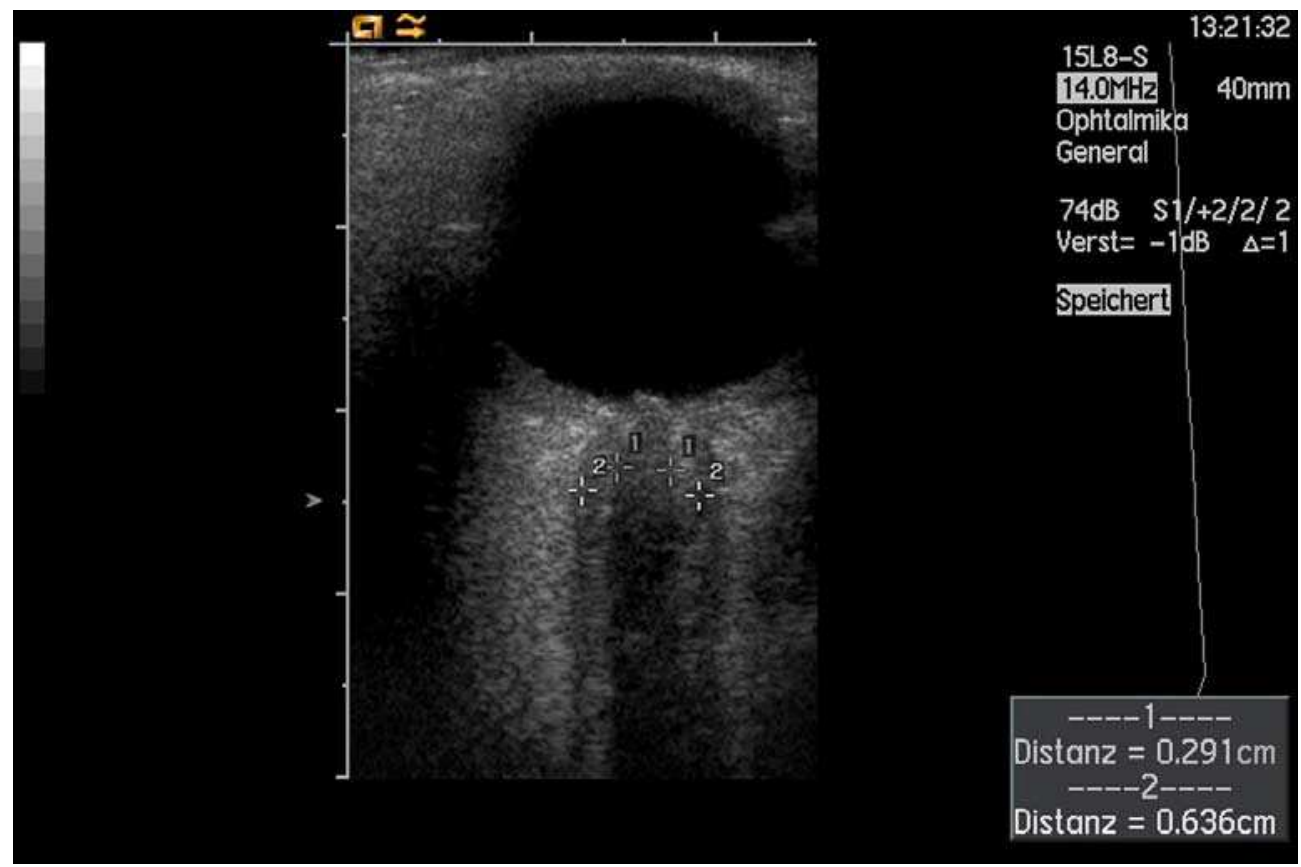

Fig. 7. Measurement of optic nerve sheath diameter using ultrasound: the optic nerve sheath is demonstrated as a thin bilateral hyperechogenic line surrounding the hypoechogenic optic nerve. The diameter is calculated by the distance of the two cursors named " 2 ". Normal values range from 5,7-6,0 $\mathrm{mm}$ with a definitely pathologic diameter in this patient 
brain injury also showed a good accuracy of the ultrasound technique. The pooled sensitivity for the detection of raised ICP was $90 \%$ (Dubourg et al. 2011). In the hands of experienced sonographers and standardized examination procedures several studies demonstrated a high intra- and interoberserver reliability (Ballantyne et al. 2002; Helmke and Hansen 1996).

Apart from the above mentioned symptomatic causes of raised ICP in idiopathic intracranial hypertension (IIH), also often referred to as pseudotumor cerebri, the mechanism of ICP increase are still not well understood. Classically patients, often obese women during childbearing age, present with headache and loss of visual acuity or visual field deficits (Degnan and Levy 2011). Though not being a life threatening condition it is still associated with permanent, and partly severe, visual deficits (Friedman 2001; Lueck and Mcllwaine 2002; Rowe and Sarkies 1998; Wall 2010). Visual symptoms are thought to be due to transient or permanent ischemic damage to the optic nerve caused by pressure (Jaggi et al. 2010; Wall 2010). Regular ophthalmologic follow-up examinations with visual acuity tests and fundoscopy are recommended, and patients often need to reduce weight and need to be treated with diuretic drugs (esp. acetazolamide), regular lumbar punctures or even operative shunt techniques.

Bäuerle et al. performed a prospective study to evaluate the immediate correlation of optic nerve diameter (OND), ONSD and papilledema with CSF-pressure reduction caused by therapeutic lumbar puncture in patients with IIH. Patients with IIH showed a significantly enlarged ONSD ( $6.4 \pm 0.6 \mathrm{~mm}$ bilaterally) compared with healthy individuals $(5.4 \pm 0.5 \mathrm{~mm})$ and a significant decrease in ONSD (right ONSD $5.8 \pm 0.7 \mathrm{~mm}, \mathrm{p}<0.004$; left ONSD $5.9 \pm 0.7$ $\mathrm{mm}, \mathrm{p}<0.043) 24$ hours after lumbar puncture (Bauerle and Nedelmann 2011). In some patients with IIH, though, the ONSD did not change at all after lumbar puncture. This could be an effect of a postulated optic nerve compartment syndrome, an idea which first came up with persistent papilledema and visual disturbance in IIH-patients despite a functioning lumbo-peritoneal shunt (Kelman et al. 1991). Pathologic changes in trabecular structures of the ONS might interfere with the physiologic bidirectional flow of the CSF to the basal cisterns leading to persistent optic disc swelling (Killer et al. 2007). Years ago, Ossoinig suggested the use of the stretch-test (originally called the "30 degrees-test"): in widened optic nerve patterns due to fluid around the optic nerve parenchyma, a decreased optic nerve thickness was observed after performing the stretch-test (positive test result), whereas in solid lesions of the optic nerve no change of optic nerve thickness was found (negative test result) (Haritoglou et al. 2002). In patients with increased ICP due to any cause, either ophthalmoscopic evaluation or bilateral retrobulbar ultrasound is mandatory, as asymmetric and unilateral papilledemae in patients with IIH are well described (Seggia and De Menezes 1993). In addition, Bäuerle et al. did not find any correlation of papilledema and OND with CSF reduction in the short-term follow-up. Due to anatomic reasons the anterior segment of the ONSD responds quickly to changes of CSF pressure. This is a particular advantage of retrobulbar ultrasound compared to funduscopic re-evaluations, as changes behind the level of the optic disc cannot be visualized by the latter technique.

Although papilledema does not quickly respond to changes in CSF-pressure it is a manifestation of chronic ICP-increase (Villa et al. 1997) and other diseases as optic neuritis (Ashurst et al. 2010) for example. 
To find a proper scanning plane, the probe is set as described above, with a good view on the optic nerve in the axial plane. The plane with the maximum disc elevation or excavation is selected, the measurements are performed in the "freeze" mode: disc elevation is quantified by putting the first caliper on the uppermost part of the swollen disc, the second caliper is positioned on the strongly reflecting line representing the lamina cribrosa (Fig. 8).

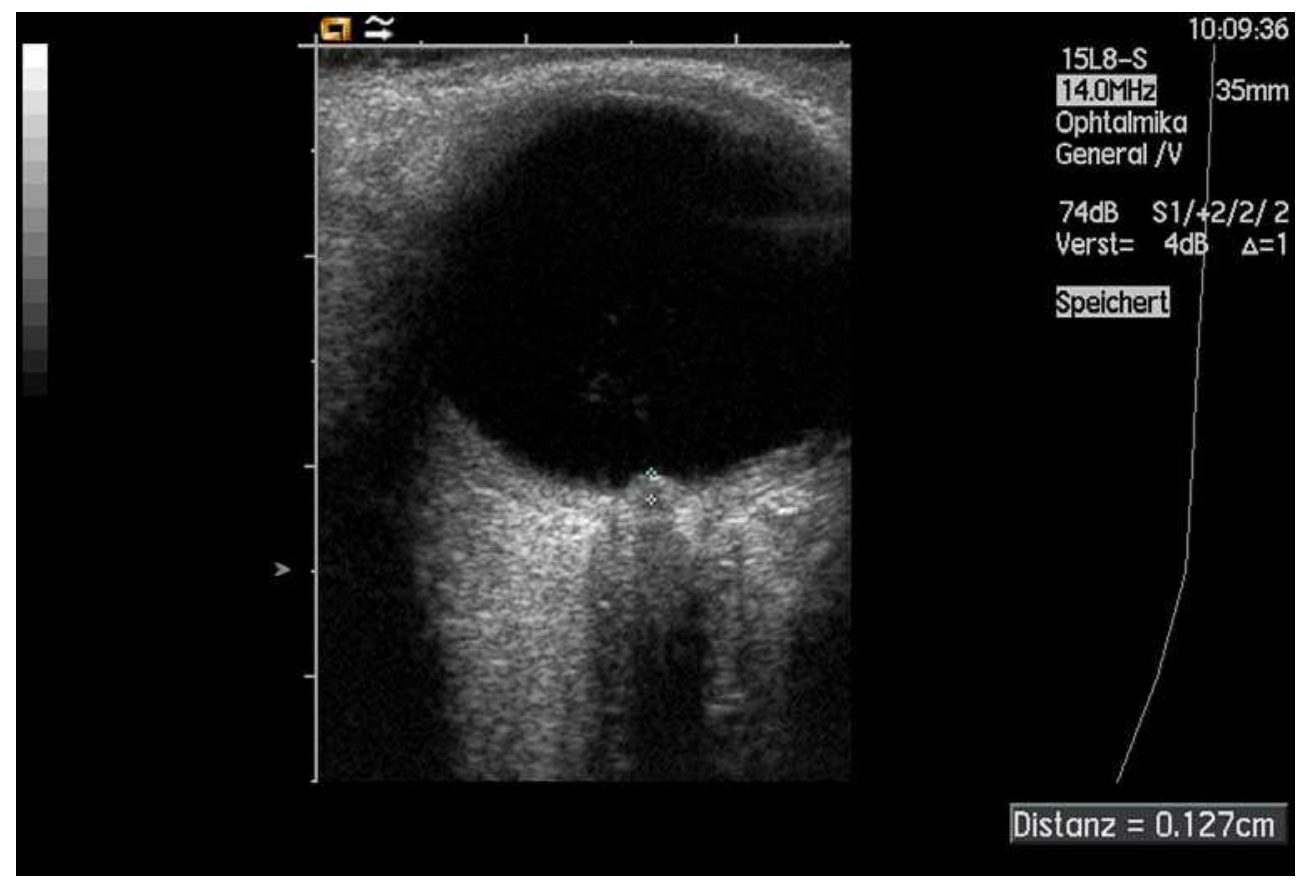

Fig. 8. Measurement of papilledema using ultrasound: disc elevation is quantified by putting the first caliper on the uppermost part of the swollen disc, the second caliper is positioned on the strongly reflecting line representing the lamina cribrosa

In patients with IIH the severity of disc swelling seems to have prognostic implications as well: in a combined retrospective and prospective study Wall et al. found a significant correlation of the severity of papilledema in patients with asymmetric papilledema and $\mathrm{IIH}$, and their visual deficits (Wall and White 1998). This underlies the importance of regular follow-up quantification of optic disc swelling in these patients. Quantification of optic disc swelling is a reliable and reproducible technique, which was demonstrated by Tamburelli et al (Tamburrelli et al. 2000). In their study, data from patients with IIH taken by a confocal scanning laser ophthalmoscope were compared to ultrasound measurements demonstrating a good correlation. The mean depth measurements ranged from 0.68 to $2.01 \mathrm{~mm}(1.17+/-$ $0.38 \mathrm{~mm})$ and were comparable to those quantified by a confocal scanning laser ophthalmoscope (0.45 to $1.23 \mathrm{~mm}(0.93+/-0.24 \mathrm{~mm})$ ) (Tamburrelli et al. 2000).

Retrobulbar sonography is an inexpensive, quick, safe and reliable tool to monitor ICP changes. It is relatively easy to learn compared to transcranial duplex sonography, which improves inter-observer reliability. Still, in critically ill patients, invasive ICP measurement 
techniques remain the gold standard but can be complemented by using orbital ultrasound. In IIH ONSD measurements are a suitable alternative to funduscopy for nonophthalmologists in the long-term follow up.

\section{Miscellaneous}

In clinical practice the neurologist is sometimes faced with the problem to discriminate between papilledema and pseudopapilledema. Papilledema is a correlate for raised ICP. A complete diagnostic workup to find the underlying cause is mandatory.

A common cause for pseudopapilledema are optic disc drusen. They can be an incidental finding in routine ophthalmologic exams. Most optic disc drusen remain asymptomatic (Davis and Jay 2003), but upon thorough investigation visual field defects can be detected in up to $90 \%$ (Gaynes and Towle 1967; Savino et al. 1979). The funduscopic discrimination between papilledema and pseudopapilledema is not trivial, as the term "pseudopapilledema" already indicates. Typical signs of true papilledema in funduscopy are cotton wool spots, multiple hemorrhages around the disc, hyperemia, venous congestion, and exudates.

Drusen consist of calcific dispositions in the optic nerve head and can be depicted as highreflectance spots in the anterior optic nerve, especially after lowering the gain. Therefore retrobulbar b-mode-sonography can help to confirm the diagnosis of optic disc drusen if the fundoscopy is not decisive (Fig. 9).
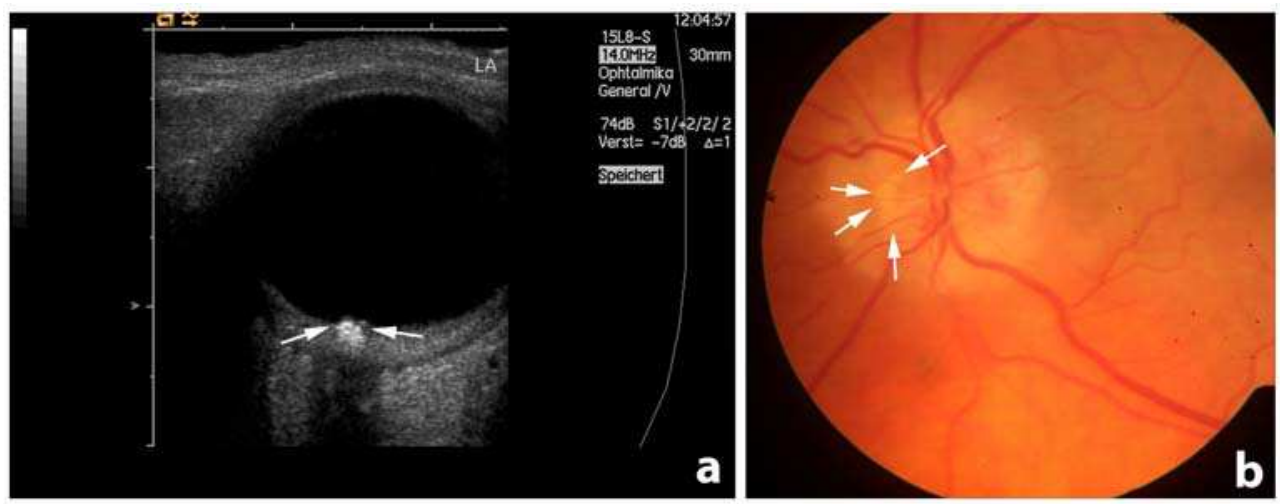

Fig. 9. Optic disc drusen seen in funduscopy and high-resolution ultrasound: (a) B-mode sonography: calcific dispositions in the optic nerve head representing optic disc drusen. (b) Fundoscopy: nasally located superficial drusen, blurred rim of optic disc, optic disc edema and hyperemia

\section{References}

American Institute of Ultrasound in Medicine (2000). "Section 7--discussion of the mechanical index and other exposure parameters. American Institute of Ultrasound in Medicine." J Ultrasound Med 19(2): 143-148, 154-168. 
Antonelli, M., E. Azoulay, M. Bonten, J. Chastre, G. Citerio, G. Conti, D. De Backer, F. Lemaire, H. Gerlach, J. Groeneveld, G. Hedenstierna, D. Macrae, J. Mancebo, S. M. Maggiore, A. Mebazaa, P. Metnitz, J. Pugin, J. Wernerman and H. Zhang (2009). "Year in review in Intensive Care Medicine, 2008: I. Brain injury and neurology, renal failure and endocrinology, metabolism and nutrition, sepsis, infections and pneumonia." Intensive Care Med 35(1): 30-44.

Arida, A., M. Kyprianou, M. Kanakis and P. P. Sfikakis (2010). "The diagnostic value of ultrasonography-derived edema of the temporal artery wall in giant cell arteritis: a second meta-analysis." BMC Musculoskelet Disord 11: 44.

Arning, C., B. Widder, G. M. von Reutern, H. Stiegler and M. Gortler (2010). "[Revision of DEGUM ultrasound criteria for grading internal carotid artery stenoses and transfer to NASCET measurement]." Ultraschall Med 31(3): 251-257.

Ashurst, J., J. Schofer and P. Sierzenski (2010). "Unilateral papilledema: a case of optic neuritis diagnosed with bedside ocular sonography." Del Med J 82(4): 137-139.

Ballantyne, S. A., G. O'Neill, R. Hamilton and A. S. Hollman (2002). "Observer variation in the sonographic measurement of optic nerve sheath diameter in normal adults." Eur J Ultrasound 15(3): 145-149.

Bauerle, J. and M. Nedelmann (2011). "Sonographic assessment of the optic nerve sheath in idiopathic intracranial hypertension." J Neurol.

Blaivas, M., D. Theodoro and P. R. Sierzenski (2003). "Elevated intracranial pressure detected by bedside emergency ultrasonography of the optic nerve sheath." Acad Emerg Med 10(4): 376-381.

Brain Trauma Foundation (2000). "The Brain Trauma Foundation. The American Association of Neurological Surgeons. The Joint Section on Neurotrauma and Critical Care. Recommendations for intracranial pressure monitoring technology." J Neurotrauma 17(6-7): 497-506.

Brown, G. C. and L. E. Magargal (1982). "Central retinal artery obstruction and visual acuity." Ophthalmology 89(1): 14-19.

Davis, P. L. and W. M. Jay (2003). "Optic nerve head drusen." Semin Ophthalmol 18(4): 222242.

Degnan, A. J. and L. M. Levy (2011). "Pseudotumor Cerebri: Brief Review of Clinical Syndrome and Imaging Findings." AJNR Am J Neuroradiol.

Dubourg, J., E. Javouhey, T. Geeraerts, M. Messerer and B. Kassai (2011). "Ultrasonography of optic nerve sheath diameter for detection of raised intracranial pressure: a systematic review and meta-analysis." Intensive Care Med.

Food and Drug Administration (2008). "Food and Drug Administration: Information for Manufacturers Seeking Clearance of Diagnostic Ultrasound Systems and Transducers."

Foroozan, R., P. J. Savino and R. C. Sergott (2002). "Embolic central retinal artery occlusion detected by orbital color Doppler imaging." Ophthalmology 109(4): 744-747; discussion 747-748.

Friedman, D. I. (2001). "Papilledema and pseudotumor cerebri." Ophthalmol Clin North Am 14(1): 129-147, ix.

Galetta, S., S. F. Byrne and J. L. Smith (1989). "Echographic correlation of optic nerve sheath size and cerebrospinal fluid pressure." J Clin Neuroophthalmol 9(2): 79-82.

Gaynes, P. M. and P. A. Towle (1967). "Hemorrhage in hyaline bodies (drusen) of the optic disc during an attack of migraine." Am J Ophthalmol 63(6): 1693-1696. 
Geeraerts, T., Y. Launey, L. Martin, J. Pottecher, B. Vigue, J. Duranteau and D. Benhamou (2007). "Ultrasonography of the optic nerve sheath may be useful for detecting raised intracranial pressure after severe brain injury." Intensive Care Med 33(10): 1704-1711.

Geeraerts, T., S. Merceron, D. Benhamou, B. Vigue and J. Duranteau (2008). "Non-invasive assessment of intracranial pressure using ocular sonography in neurocritical care patients." Intensive Care Med 34(11): 2062-2067.

Girisgin, A. S., E. Kalkan, S. Kocak, B. Cander, M. Gul and M. Semiz (2007). "The role of optic nerve ultrasonography in the diagnosis of elevated intracranial pressure." Emerg Med J 24(4): 251-254.

Gold, D. (1977). "Retinal arterial occlusion." Trans Sect Ophthalmol Am Acad Ophthalmol Otolaryngol 83(3 Pt 1): OP392-408.

Hansen, H. C. and K. Helmke (1997). "Validation of the optic nerve sheath response to changing cerebrospinal fluid pressure: ultrasound findings during intrathecal infusion tests." J Neurosurg 87(1): 34-40.

Haritoglou, C., H. Herzum, O. Ehrt, K. C. Ossoinig and A. Kampik (2002). "[Echographic differential diagnosis of optic nerve widening]." Ophthalmologe 99(7): 559-565.

Helmke, K. and H. C. Hansen (1996). "Fundamentals of transorbital sonographic evaluation of optic nerve sheath expansion under intracranial hypertension II. Patient study." Pediatr Radiol 26(10): 706-710.

Hiler, M., M. Czosnyka, P. Hutchinson, M. Balestreri, P. Smielewski, B. Matta and J. D. Pickard (2006). "Predictive value of initial computerized tomography scan, intracranial pressure, and state of autoregulation in patients with traumatic brain injury." J Neurosurg 104(5): 731-737.

Jaggi, G. P., M. Harlev, U. Ziegler, S. Dotan, N. R. Miller and H. E. Killer (2010). "Cerebrospinal fluid segregation optic neuropathy: an experimental model and a hypothesis." Br J Ophthalmol 94(8): 1088-1093.

Kelman, S. E., R. C. Sergott, G. A. Cioffi, P. J. Savino, T. M. Bosley and M. J. Elman (1991). "Modified optic nerve decompression in patients with functioning lumboperitoneal shunts and progressive visual loss." Ophthalmology 98(9): 1449-1453.

Killer, H. E., G. P. Jaggi, J. Flammer, N. R. Miller, A. R. Huber and A. Mironov (2007). "Cerebrospinal fluid dynamics between the intracranial and the subarachnoid space of the optic nerve. Is it always bidirectional?" Brain 130(Pt 2): 514-520.

Lieb, W. E., S. M. Cohen, D. A. Merton, J. A. Shields, D. G. Mitchell and B. B. Goldberg (1991). "Color Doppler imaging of the eye and orbit. Technique and normal vascular anatomy." Arch Ophthalmol 109(4): 527-531.

Lizzi, F. L., A. J. Packer and D. J. Coleman (1978). "Experimental cataract production by high frequency ultrasound." Ann Ophthalmol 10(7): 934-942.

Lueck, C. and G. McIlwaine (2002). "Interventions for idiopathic intracranial hypertension." Cochrane Database Syst Rev(3): CD003434.

Mawn, L. A., T. R. Hedges, 3rd, W. Rand and P. A. Heggerick (1997). "Orbital color Doppler imaging in carotid occlusive disease." Arch Ophthalmol 115(4): 492-496.

McFadzean, R. M. (1998). "Ischemic optic neuropathy and giant cell arteritis." Curr Opin Ophthalmol 9(6): 10-17.

Muller, M., K. Wessel, E. Mehdorn, D. Kompf and C. M. Kessler (1993). "Carotid artery disease in vascular ocular syndromes." J Clin Neuroophthalmol 13(3): 175-180.

Newman, W. D., A. S. Hollman, G. N. Dutton and R. Carachi (2002). "Measurement of optic nerve sheath diameter by ultrasound: a means of detecting acute raised intracranial pressure in hydrocephalus." Br J Ophthalmol 86(10): 1109-1113. 
Paivansalo, M., K. Riihelainen, T. Rissanen, I. Suramo and L. Laatikainen (1999). "Effect of an internal carotid stenosis on orbital blood velocity." Acta Radiol 40(3): 270-275.

Pfaffenbach, D. D. and R. W. Hollenhorst (1972). "Morbidity and survivorship of patients with embolic cholesterol crystals in the ocular fundus." Trans Am Ophthalmol Soc 70: 337-349.

Rowe, F. J. and N. J. Sarkies (1998). "Assessment of visual function in idiopathic intracranial hypertension: a prospective study." Eye (Lond) 12 ( Pt 1): 111-118.

Savino, P. J., J. S. Glaser and M. A. Rosenberg (1979). "A clinical analysis of pseudopapilledema. II. Visual field defects." Arch Ophthalmol 97(1): 71-75.

Schlachetzki, F., S. Boy, U. Bogdahn, H. Helbig and M. A. Gamulescu (2010). "The Retrobulbar "Spot Sign" - Ocular Sonography for the Differential Diagnosis of Temporal Arteritis and Sudden Blindness." Ultraschall Med.

Seggia, J. C. and M. L. De Menezes (1993). "[Pseudotumor cerebri without optic papilledema]." Arq Neuropsiquiatr 51(4): 511-518.

Soldatos, T., D. Karakitsos, K. Chatzimichail, M. Papathanasiou, A. Gouliamos and A. Karabinis (2008). "Optic nerve sonography in the diagnostic evaluation of adult brain injury." Crit Care 12(3): R67.

Tamburrelli, C., T. Salgarello, C. G. Caputo, A. Giudiceandrea and L. Scullica (2000). "Ultrasonographic evaluation of optic disc swelling: comparison with CSLO in idiopathic intracranial hypertension." Invest Ophthalmol Vis Sci 41(10): 2960-2966.

Tayal, V. S., M. Neulander, H. J. Norton, T. Foster, T. Saunders and M. Blaivas (2007). "Emergency department sonographic measurement of optic nerve sheath diameter to detect findings of increased intracranial pressure in adult head injury patients." Ann Emerg Med 49(4): 508-514.

Toms, D. A. (2006). "The mechanical index, ultrasound practices, and the ALARA principle." J Ultrasound Med 25(4): 560-561; author reply 561-562.

Tranquart, F. O., O. Bergès, P. Koskas, S. Arsene, C. Rossazza, P.-J. Pisella and L. a. Pourcelot (2003). "Color doppler imaging of orbital vessels: Personal experience and literature review." Journal of Clinical Ultrasound 31(5): 258-273.

Tsung, J. W., M. Blaivas, A. Cooper and N. R. Levick (2005). "A rapid noninvasive method of detecting elevated intracranial pressure using bedside ocular ultrasound: application to 3 cases of head trauma in the pediatric emergency department." Pediatr Emerg Care 21(2): 94-98.

Villa, A. M., S. F. Anderson and R. E. Abundo (1997). "Bilateral disc edema in retinitis pigmentosa." Optom Vis Sci 74(3): 132-137.

Wall, M. (2010). "Idiopathic intracranial hypertension." Neurol Clin 28(3): 593-617.

Wall, M. and W. N. White, 2nd (1998). "Asymmetric papilledema in idiopathic intracranial hypertension: prospective interocular comparison of sensory visual function." Invest Ophthalmol Vis Sci 39(1): 134-142.

Watanabe, A., H. Kinouchi, T. Horikoshi, M. Uchida and K. Ishigame (2008). "Effect of intracranial pressure on the diameter of the optic nerve sheath." J Neurosurg 109(2): 255-258.

Winkler, F., S. Kastenbauer, T. A. Yousry, U. Maerz and H. W. Pfister (2002). "Discrepancies between brain CT imaging and severely raised intracranial pressure proven by ventriculostomy in adults with pneumococcal meningitis." J Neurol 249(9): 1292-1297. 


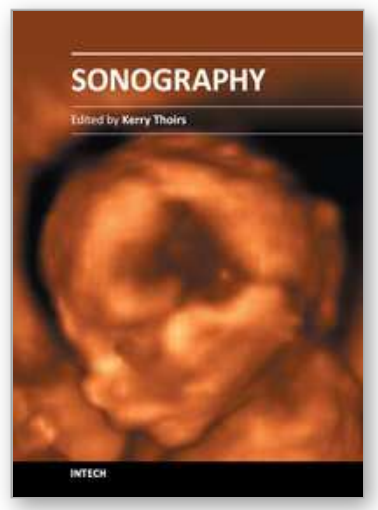

\author{
Sonography \\ Edited by Dr. Kerry Thoirs
}

ISBN 978-953-307-947-9

Hard cover, 346 pages

Publisher InTech

Published online 03, February, 2012

Published in print edition February, 2012

Medical sonography is a medical imaging modality used across many medical disciplines. Its use is growing, probably due to its relative low cost and easy accessibility. There are now many high quality ultrasound imaging systems available that are easily transportable, making it a diagnostic tool amenable for bedside and office scanning. This book includes applications of sonography that can be used across a number of medical disciplines including radiology, thoracic medicine, urology, rheumatology, obstetrics and fetal medicine and neurology. The book revisits established applications in medical sonography such as biliary, testicular and breast sonography and sonography in early pregnancy, and also outlines some interesting new and advanced applications of sonography.

\title{
How to reference
}

In order to correctly reference this scholarly work, feel free to copy and paste the following:

Michael Ertl, Maria-Andreea Gamulescu and Felix Schlachetzki (2012). Application of Orbital Sonography in Neurology, Sonography, Dr. Kerry Thoirs (Ed.), ISBN: 978-953-307-947-9, InTech, Available from: http://www.intechopen.com/books/sonography/application-of-orbital-sonography-in-neurology

\section{INTECH}

open science | open minds

\section{InTech Europe}

University Campus STeP Ri Slavka Krautzeka 83/A 51000 Rijeka, Croatia Phone: +385 (51) 770447 Fax: +385 (51) 686166 www.intechopen.com

\section{InTech China}

Unit 405, Office Block, Hotel Equatorial Shanghai No.65, Yan An Road (West), Shanghai, 200040, China 中国上海市延安西路65号上海国际贵都大饭店办公楼 405 单元 Phone: +86-21-62489820

Fax: +86-21-62489821 
(C) 2012 The Author(s). Licensee IntechOpen. This is an open access article distributed under the terms of the Creative Commons Attribution 3.0 License, which permits unrestricted use, distribution, and reproduction in any medium, provided the original work is properly cited. 